\title{
Stage IV Acral Lentiginous Melanoma AJCC v6 and v7
}

National Cancer Institute

\section{Source}

National Cancer Institute. Stage IV Acral Lentiginous Melanoma AJCC v6 and v7. NCI

Thesaurus. Code C8784.

Stage IV includes: (Any T, Any N, M1). M1: Distant metastasis. (from AJCC 6th and 7th Eds.) 